\title{
Substantial gadolinium enrichments in lake and river near metrocities in Korea
}

\author{
INTAE KIM ${ }^{123}$ \\ ${ }^{1}$ Marine Environmental Research Center, Korea Institute of \\ Ocean Science and Technology, Busan 49111, South \\ Korea (email: ikim@kiost.ac.kr)
}

We measured dissolved rare earth elements (REEs) in the water samples from Shihwa Lake (SL), which was assumed to be highly polluted, as well as in the downstream portion of the Han River (HR), which runs through, Seoul, Korea. Among the investigated REEs, only Gadolinium (Gd) was found to be significantly enhanced after REE concentrations were shale-normalized ( $\mathrm{SN})$. The calculated $\mathrm{Gd}$ anomaly $\left(\mathrm{Gd} / \mathrm{Gd}^{*}=3 \times \mathrm{Gd}_{\mathrm{SN}} /\left(\mathrm{Sm}_{\mathrm{SN}}+2 \times \mathrm{Tb}_{\mathrm{SN}}\right)\right)$ was about $1.5 \pm 0.1$ $(n=16)$ in SL and $1.6 \pm 0.3$ in HR $(n=26)$ water relative to other types of natural water such as groundwater, seawater, and river water in uncontaminated areas $\left(\mathrm{Gd} / \mathrm{Gd}^{*} \sim 1.2\right.$, $\mathrm{n}>400$ ). These significant $\mathrm{Gd}$ anomalies seem to be due to the inputs of anthropogenic $\mathrm{Gd}\left(\mathrm{Gd}_{\mathrm{anth}}\right)$, especially by the use of Gd-based contrast agents for magnetic resonance imaging (MRI) tests from a number of hospitals and medical institutes surrounding our study areas. The Gdanth inventory was estimated to be $190 \pm 80 \mathrm{~g}$ and $680 \pm 360 \mathrm{~kg} \mathrm{Gd}$ in SL and the HR (watersheds in our study area), respectively. The $\mathrm{Gd}_{\text {anth }}$ flux to the Yellow Sea from the HR is estimated to be $530 \pm 330 \mathrm{~g} \mathrm{Gd} \mathrm{day}^{-1}$. Overall, these results suggest that quantitative evaluation of man-made REEs for associated human risk assessments are needed, because considerable amounts of REEs are now used by modern high-tech industries. 